\title{
The Effect Of Direct Instruction Model On Intermediate Class Achievement And Attitudes Toward English Grammar
}

Rubina Kousar, Pir Mehr Ali Shah Arid Agriculture University, Pakistan

\begin{abstract}
This study was aimed at investigating the effect of the direct instruction model on intermediate class achievement and attitudes toward English grammar. It was an experimental study and the purpose was to explore the relative effectiveness of instructional methodology (independent variable) on students' achievement and attitude (dependent variables). This study is based on Slavin's (1987) components of Direct Instruction. Direct Instruction (DI) refers to academically focused, teacher-directed classroom instruction using sequenced and structured materials. It refers to teaching activities where goals are clear to students, time allocated for instruction is sufficient and continuous, and feedback to students is immediate and academically oriented. On the other hand, in traditional lessons, the instructor verbalizes information to passive note-taking by students. The instructor thinks that students have empty minds which are to be filled with knowledge. Students are expected to record and absorb knowledge (Slavin, 1994). In Pakistan, this approach is still unfamiliar to practitioners and researchers in education, including teachers of English language at the intermediate level. The main objectives of the study were: 1) to measure the achievement of the experimental and control groups after providing treatment of direct instruction to the experimental group, 2) to measure the attitude of the experimental and control groups after providing treatment of direct instruction to the experimental group, 3) to compare the achievement of the experimental group with the control group after experiment and to compare the high achievers and low achievers of the experimental and control group, 4) to compare the attitude of the experimental and control groups toward English grammar after providing treatment of direct instruction, and 5) to compare the effect of direct instruction on the retention of students in English grammar. To achieve the above-mentioned objectives, null hypotheses were formulated and tested. The sample of the study comprised of 52 first year students who were matched on their ability in English grammar and placed into an experimental group or control group on the basis of specially-designed pre-tests. The study was conducted in Cantt College for Women Wah Cantt. A valid and reliable pre-test and post-test in English grammar were developed to measure the achievement of students in English grammar. An attitude scale was developed to measure the attitude of the students toward English grammar, and it was administered before and after the treatment. The experimental group was taught through direct instruction and the control group was taught, as usual, through the traditional approach for a period of three months. Chi-square and t-tests were applied to test the null hypotheses, and .05 was selected as the level of significance. The results of Direct Instruction Model were consistently better than those of traditional instruction, both in terms of achievement and attitude. After an interval of six weeks, the students taught through DI also showed better retention.
\end{abstract}

Keywords: DI, Direct Instruction

\section{INTRODUCTION}<smiles>[C]1CCCCC1</smiles>
$\mathrm{n}$ order to teach effectively, the teacher must have sufficient knowledge about the students, as well as the knowledge about the subject and appropriate methods of teaching. Modern research indicates that if proper and suitable methods and techniques are used, even the students of normal intelligence can easily learn. It is the teacher's responsibility to see that the lessons are taught in such a manner that the child-related goals are met. To do so, the teacher must understand the requirements of the program and be able to teach using appropriate skills and techniques. For the solution of these individual differences and for the better results from the learners, four teaching models have been developed; namely, direct instruction, cooperative learning, mastery 
learning and problem-based instruction. These models of instruction have proven to be successful in enhancing learning outcomes. Direct Instruction is highly structured and teacher-directed which maximizes student learning time. Mastery Learning implies giving enough time and quality instruction, whereby nearly all students can master any set of objectives. Cooperative Learning is focused on working in groups. Problem-based instruction provides students with the opportunity to explore real issues (Sadker and Sadker, 1997). The first two models are teachercentered, while the latter two are learner-centered.

In Pakistan, the direct instruction model has not yet been put through rigorous testing. It is, therefore, desirable that this strategy of teaching be tried out through experimental studies in actual classrooms in order to determine if student achievement and attitudes are enhanced.

Moreover, research on the Direct Instruction model has had mixed conclusions. First, it is important to remember that the research on Direct Instruction has mainly focused on basic reading and mathematics mostly in the elementary grades. For other subjects and at other grade levels, we have less of a basis for believing that Direct Instruction methods will improve students' learning. Thirty years of experimental research shows that Direct Instruction fosters rapid and durable gains in the basic skills of language arts (vocabulary, interaction competence, reading, spelling, and writing, math, and science). Second, all the studies conducted in this area have a number of conflicting results about this method of teaching. According to some research findings, the DI approach has a positive effect on improving the academic achievement, and some critics say that DI has negative effects or no effect on their students' academic achievement. Third, all of the above studies are limited to only finding the effectiveness of academic achievement of students, not their attitudes toward subjects (Gagne, 1992).

\section{POPULATION \& SAMPLE}

The sample consisted of 52 female students studying English grammar in the first-year class at Cantt College for Women Wah Cantt, who were assigned to experimental and control groups by matching them on the basis of their pre-test achievement scores. Each group consisted of 26 female students. The students at this school were firstly chosen due to cooperation of the head and availability of appropriate time and secondly because this school had one section of the first- year class that met the required criteria for sampling of the study and for comparison. There was no school indigenously meeting these criteria. Thirdly, the head of the school facilitated the researcher in satisfactorily working with her staff. Fourthly, both teachers of the experiment and controlled groups had almost the same qualifications and experience.

\section{RESEARCH INSTRUMENTS}

In order to measure the achievement of sample students before and after the study in the subject of English grammar, a pre-test, post-test, retention test and attitude scale were developed for the study. An achievement test (pre-test and post-test) consisted of completion items, True and False items; multiple choice items; matching column items, and rearranging items.

To measure the attitude of sample students toward the subject of English grammar, an attitude scale was developed after adapting the one used by Sarwat (2004). The scale consisted 34 items based on a 3-point scale (agree, undecided, disagree).

\section{SELECTION AND TRAINING OF TEACHERS FOR THE EXPERIMENT}

Criteria for the selection of teachers for teaching the experimental and control groups were that they were regular staff members of Cantt College for Women Wah Cantt. They possessed almost identical academic qualifications, they had equal professional qualifications, and they possessed equal teaching experience. 


\section{MATERIAL}

The material used in the study comprised of lessons plans. In order to conduct the experiment, the researcher developed lesson plans and worksheets for all topics. The lesson plans were formulated according to the guidelines on Direct Instruction provided by Slavin (1994) and Direct Instruction lesson plans suggested by Hunter (1984).

\section{DATA COLLECTION}

The pre-testing of the sample students was carried out in the classrooms where they were informed that the test had nothing to do with their school exam. The post-test was the culminating activity. It was administered in the same room used for pre-testing the students. Also, the same post-test was used as the retention test after an interval of six weeks.

\section{SCORING OF DATA}

The achievement scores (pre-test, post-test and retention test) and attitude scores of the sample were computed. The pre-test, post-test and retention test were scored according to the keys.

The responses on the attitude scale were scored by assigning a ' 3 ' to the 'agree' response, a ' 2 ' to the 'undecided' response, and a ' 1 ' to the 'disagree' response. The statements reflecting negative attitudes were scored in the reverse order.

\section{ANALYSIS OF DATA}

The means, standard deviations, correlations, and significance of difference between the mean scores of both groups on the pre-test, the post-test, attitude scale and retention test were tested by applying Chi-square and ttests. The level of significance used for testing the following null hypotheses was .05:

1. There is no significant difference between the mean achievement scores of the experimental group and the control group before the experiment.

2. There is no significant difference between the mean attitude scores of the experimental group and the control group before the experiment.

3. There is no significant difference between the mean achievement scores of the experimental group and the control group after the experiment.

4. There is no significant difference between the mean achievement scores of high achievers of the experimental group and the control group after the experiment.

5. There is no significant difference between the mean achievement scores of low achievers of the experimental group and the control group after the experiment.

6. There is no significant difference between the mean attitude scores of the experimental group and the control group after the experiment.

7. There is no significant interaction between the mean achievement scores of high achievers and low achievers of the experimental group and the control group after the treatment.

8. There is no significant interaction between the mean attitude scores of high achievers and low achievers of the experimental group and the control group after the treatment.

9. There is no significant difference between the mean retention scores of the experimental group and the control group after six weeks of the experiment.

10. There is no significant difference between the mean retention scores of low achievers of the experimental group and the control group after six weeks of the experiment.

\section{RESULTS}

Tables can be obtained from the author at hamdan_yahoo.com. 


\section{DISCUSSION}

Effective instructional methodology forms the basis of successful teaching.

The most important aspect of instructional quality is the degree to which the lesson makes sense when it becomes meaningful to the students. It becomes meaningful when the new information relates to their prior knowledge, what Piaget refers to as 'assimilation'. Ausubel's concept of advanced organizer also promotes meaningfulness of the new material. Advanced organizers are the statements, activities and techniques which establish a framework that orient the students before these are actually presented. These are the bridges between what the student already knows and what is to be taught. These provide the student with a big picture of what is to come and how information is meaningfully and sensibly connected.

The results of the present study are consistent with those arrived at by Slavin (1994), Gagne (1985), Gagne and Briggs (1992), Rosenshine (1995), Hunter (1982), and Good and Grouws (1979) who reported that the Direct Instructional model works well when focused on the activities of the teacher, teacher/student interaction at every event in the lesson, controlling student behavior, relating the current lesson to previous and future lessons, reviewing prerequisites, presenting new material, asking relevant questions, conducting learning probes, providing dependent practice, assessing performance and providing feedback, and giving students an opportunity to work alone through independent practice before assigning homework.

Direct Instruction is a behaviorist approach that states if concepts are presented in a clear, well-organized, and systematic way, children will learn (Engelmann, 1996). Originally, the model could have originated as a reinforcement model, yet its linkage is clearly with Gagne's instructional events model (which is based on the information processing theory). Similarly, David Ausubel's expository teaching is closed to DI in its approach. Expository teaching is based on the cognitive approach to learning, though it is just the converse of Brunel's discovery model which is also grounded on the cognitive approach. DI is teacher-centered instruction, like expository teaching, that seeks to change students' behavior by way of changing his thoughts. Therefore, it is also very much a cognitive approach.

The results of the present study indicate that traditional instruction did not have as much significant impact on learning English grammar as Direct Instruction because of the effective use of time in maintaining students' attention, more teacher-directed instructions, and active presentation of information. It is useful to gain students' attention and provide motivational clues and prompts. It is very helpful to present new content with sequential, relevant, transitional, and component relationships, step-by-step progression from sub-topic to sub-topic, based on task analysis. It is a powerful strategy with use of varied examples, visual prompts, and demonstrations to mediate between concrete and abstract concepts.

The DI model of teaching might also have been found more effective in this study because the subject of English grammar is more structured and more amenable to teacher-centered, systematic approaches like Direct Instruction. English grammar consists of rules and action sequences that can be more effectively learned through Direct Instruction rather than indirect instruction, as pointed out by Borich (1999). Sadker and Sadker (1997) are also of the same view, which lends adequate support to the study results and indicates the superiority of DI to the traditional, unsystematic and illogical, traditional approach to teaching.

\section{CONCLUSION}

The Direct Instructional model was found to be more effective than traditional instruction in immediate and delayed retention, as well as development of positive attitudes toward the subject of English grammar. Therefore, DI was equally beneficial for students of varying abilities.

The overall conclusion drawn from this experimental study was that the English grammar achievement of students taught by direct instruction was better than that of students taught in the routine way. 


\section{AUTHOR INFORMATION}

Rubina Kousar - basically Education teacher with M.s.c in Education, B.ed certification, Ph.D in Educational Psychology in process, one year diploma in computer sciences, with ten years' experience in teaching education at college level and five years' experience as a principal at high school level, with additional expertise in the areas of creative art and social work. Served as faculty advisor for school newspaper and taught special needs of students.

\section{REFERENCES}

1. Adams, G., and Engelmann, S. 1996. Research on Direct Instruction: 20 years Beyond DISTAR. Educational Achievement Systems. Seattle, WA, USA. http://www.darkwing.uoregon.edu.adiep [1998, November 5].

2. Ausubel, D. 1978. In defense of advance organizers: A reply to the critics. Review of Educational Research, U.S.A. Pp 48, 251-257.

3. Bruner, J. 1973 Going Beyond the Information Given, New York: Norton. Pp. 76,89,90.

4. Brorich, G. D. 1999. Observation Skills for Effective Teaching ( $3^{\text {rd }}$ ed.). Merrill Prentice Hall: New Jersey, USA.P.192.

5. $\quad$ Gagne, R. M. 1985. The Conditions of Learning $\left(4^{\text {th }}\right.$ ed.). Published by Holt, Rinehart \&Winston. New York, USA.P.83.

6. Gagne, R. and Briggs, L. 1992. Principles of Instructional Design (4th Ed.). Fort Worth, TX: HBJ College Publishers. Pp.42-50.

7. Good, T, L. and Grouws, D. 1979. The Missouri Mathematics Effectiveness Project: An achievement project in fourth-grade classrooms. Journal of educational psychology. Montreal, Canada. pp. 96,100,120.

8. Hunter, M. 1984. Knowing Teaching and Supervising. In P. Hosford (Ed.), Using What we Know about Teaching. Association for Supervision and Curriculum Development, Alexandria,USA. pp. 78-82.

9. Rosenshine, B. 1995. Advances in research on instruction. In J.W. Lloyd, E.J. Kameenui and D. Chard (Eds.) Issues in educating students with disabilities, Mahway, N.J.: Lawrence Earlbaum. Pp. 197-221.

10. Sadker, M. P. and Sadker M. S. 1997. Teacher School and Society (4 ${ }^{\text {th }}$ Ed.). McGraw hill companies, Inc, New York, USA. P. 62, 63.

11. Slavin, R. E. 1994. Educational Psychology: Theory and Practice $\left(4^{\text {th }}\right.$ Ed.). Allyn and Bacon, Boston, USA. P. 231,232,249.

12. Slavin, R. E. 1987. "The Hunterization of America's Schools." Instructor Pp96 (8):56 
NOTES 